\title{
Dutch shake up funding council, shift its emphasis
}

London. The basic research council in the Netherlands plans to shift money from individuals to large projects involving many researchers as part of an enforced restructuring. The Netherlands Organization for Scientific Research (NWO) changed course last month after having failed to convince the Dutch government to spend more on science.

This year, NWO will award 470 million guilders (US\$280 million), around 10 per cent of government spending on research, to 3,700 researchers for projects and equipment at 13 universities and at its own research institutes. NWO's governing body, the general board, allocates money to six councils, which in turn distribute grants to foundations covering 34 disciplines. The restructuring follows a threat in NWO's five-year plan that if the government did not increase its budget it would pare down its fields of interest and shrink its structure to match its budget.

Ninety per cent of NWO's budget at present goes to individual researchers, many of them at the beginning of their careers. The plan is to lower this proportion to 50 per cent and give larger subsidies to small research groups. NWO expects the slack to be taken up by the Ministry of Education and Science, which last year began to fund graduate education directly.

The restructuring affects the 34 foundations, each representing a particular research interest, through which NWO funds are channelled. NWO intends to withdraw its backing from those foundations with annual budgets below 4 million guilders on the grounds that they are too small to influence the field and are costly to administer. As well as releasing funds, the changes are

expected to simplify the grants procedure, allowing two rounds a year rather than one.

While the foundations may continue to exist to improve communications among researchers, funding will devolve to the councils. Although none has been singled out, some disciplines will undoubtedly suffer.

Seventeen of the 34 foundations and departments will lose their NWO status by May next year. They include the computer science, earth sciences and biophysics foundations, the meteorology and physical oceanography working groups and all but one of the programmes in the humanities and social sciences councils. The mathematics foundation will also lose its NWO status but its institute, the Centre for Mathematics and Computer Science in Amsterdam, is expected to remain open. The government has yet to respond, but NWO is not expecting opposition.

Meanwhile, the recession is forcing the Ministry of Education and Science to look more closely at its research budget of 4.7 billion guilders. It wants to cut library spending by 12.8 million guilders and terminate several projects on the dissemination of information. The Ministry also wants to reduce the Dutch contribution to CERN, the European Laboratory of Particle Physics, hoping that the difference will be made up by non-subscriber countries. The education ministry awards a third of its budget directly to universities, with the rest going to researchers through NWO, the Royal Netherlands Academy of Science and Letters, the Netherlands Organization for Applied Scientific Research and a number of agricultural and medical institutes under the control of other ministries.

Ian Mundell

\section{Max Planck institute gets new life}

Munich. The Max Planck Institute for Astrophysics at Garching, rumoured earlier this year to be closing, has won a stay of execution that may become permanent. Its strongest sign of life is a renewed search for a new director by the Max Planck Society, which runs nearly 60 research institutes in Germany.

The society has for more than a year been seeking a replacement for Rudolf Kippenham, who retired as director last year (see Nature 358, 267; 1992). Controversy arose when the society insisted that Kippenham be succeeded by a single director even though most institutes have a group of up to five directors to share the burden.
Scientists in Garching have always argued that a rotating system would be much easier to implement.

Now they are having their way. The society has formed a small committee with an indeterminate deadline to investigate this and the possibility of a foreign director. With the boundaries so widened, says Garching scientist Peter Schneider, the danger of closure looks much reduced.

The Max Planck Society says that talk of closure was unfounded and that its new search for a director is independent of a groundswell of support for the institute from astrophysicists around the world and in the media.

\section{US drug trials said to ignore gender differences}

Washington. Pharmaceutical companies do a poor job analysing how their proposed drugs will affect women, according to a report last week to the US Congress by the General Accounting Office that lays part of the blame on the Food and Drug Administration (FDA). The report recommends that the FDA require companies to look more closely at gender differences and to enrol a minimum number of women in clinical trials of relevant drugs.

The report examined late-stage trials for 53 new drugs approved by FDA between January 1988 and June 1991. (Women of childbearing age may not participate in earlier phases of clinical trials.) GAO says that a third of the drugs were tested in trials that included fewer than 250 female subjects, the minimum that FDA believes necessary to detect gender-related differences in drug safety and efficacy. Eight of the 13 drugs for cardiovascular disease, a leading cause of death in women, were not tested on enough women, the report found.

Fewer than half the drugs were analysed by gender, although evidence suggests that women and men react differently to some drugs. Only 12 per cent of the drugs were analysed for their reaction with either female hormones or oral contraceptives.

The report says that FDA guidelines on including women are ambiguous: they recommend that all those who will take the drug be represented in clinical trials but do not mention women. In a 1991 survey by the Pharmaceutical Manufacturers Association, nearly half of its members said that the FDA did not specify that women should be included in clinical trials. Some of the blame also falls on industry: although the FDA emphasizes the importance of analysing data for gender differences, more than half the companies submitting new drug applications in 1992 failed to do so.

The FDA says that its reviewers will begin mentioning this requirement to companies at the start of the testing process. The FDA also agrees that drug companies should analyse the way in which their products interact with female hormones and oral contraceptives.

But the agency disputes the report's claim that many drug trials enrol too few women. It believes that the figure of 250 should be a guide rather than a floor; for some drugs, testing 100 women is sufficient. FDA officials say that another problem is how to reconcile the fact that women suffer from some diseases later in life than men with restrictions on the use of the elderly as test subjects.

Traci Watson 